\title{
Neurotrophin Regulation of Gene Expression
}

\author{
Azad Bonni and Michael E. Greenberg
}

\begin{abstract}
The neurotrophins comprise a family of secreted proteins that elicit profound responses in cells of the developing and mature vertebrate nervous system including the regulation of neuronal survival and differentiation. The molecular mechanisms by which the neurotrophins exert their effects have been the subject of intense investigation. The neurotrophins elicit responses in neurons via members of the Trk family of receptors and the p75 neurotrophin receptor. Once activated, neurotrophin receptors trigger a large number of biochemical events that propagate the neurotrophin signal from the plasma membrane to the interior of the cell. An important target of the neurotrophin-induced signaling pathways is the nucleus, where neurotrophin-induced signals are coupled to alterations in gene expression. These neurotrophin-induced changes in gene expression are critical for many of the phenotypic effects of neurotrophins including the regulation of neuronal survival and differentiation.
\end{abstract}

\begin{abstract}
RÉSUMÉ: Régulation de l'expression génique par les neurotrophines. Les neurotrophines incluent une famille de protéines sécrétées qui provoquent des réponses intenses au niveau des cellules du système nerveux en développement et adulte chez les vertébrés, incluant la régulation de la survie et la différenciation neuronale. Les mécanismes moléculaires par lesquels les neurotrophines exercent leurs effets ont été le sujet d'investigations poussées. Les neurotrophines provoquent des réponses neuronales via des récepteurs qui sont membres de la famille Trk et le récepteur de la neurotrophine p75. Une fois activés, les récepteurs de la neurotrophine déclenchent plusieurs réactions biochimiques qui propagent le signal de la neurotrophine de la membrane plasmique à l'intérieur de la cellule. Le noyau est une cible importante des voies de signalisation sensibles à la neurotrophine où les signaux induits par les neurotrophines sont couplés à des changements dans l'expression génique. Ces changements dans l'expression génique induits par les neurotrophines sont critiques pour plusieurs effets phénotypiques des neurotrophines, dont la régulation de la survie et de la différenciation neuronale.
\end{abstract}

Can. J. Neurol. Sci. 1997; 24: 272-283

The discovery of nerve growth factor over forty years ago and the extensive characterization of its trophic effects in the peripheral nervous system ${ }^{1}$ stimulated research into the identification of novel proteins that promote the survival of distinct populations of neurons including those that reside in the central nervous system. Over the past decade, four other neurotrophins have been characterized and cloned. These consist of brain derived neurotrophic factor (BDNF), neurotrophin 3 (NT-3), NT-4/5, and NT-6. Recent studies have revealed that in addition to their trophic effects, the neurotrophins elicit a wide variety of responses in the nervous system including the regulation of the proliferation and differentiation of neuronal precursor cells in the developing nervous system.

\section{Biological ACtivities of the NeUrotrophins}

Current concepts of neurotrophin function stem principally from four types of experimental approaches. Studies of the expression pattern of the neurotrophins and their receptors have provided important clues regarding the site and nature of neurotrophin function. Extensive work characterizing the biological activities of the neurotrophins in primary neuronal cultures and the use of neutralizing antibodies in vivo have enhanced our understanding of the physiologic role of the neurotrophins.
Finally, gene targeting of each neurotrophin and its cognate receptor has confirmed some of the functions of the neurotrophins that were predicted by the other three experimental approaches but has cast doubt on other functions. In addition to their functions during the development of the nervous system, the neurotrophins can promote the recovery of neurons in the adult nervous system following injury. ${ }^{2,3}$ These observations have generated interest in the therapeutic potential of the neurotrophins in degenerative disorders of the nervous system. An overview of the biological activities of the neurotrophins, which have been reviewed extensively, ${ }^{4-6}$ will be presented here.

\section{Peripheral Nervous System}

The biological activities of the neurotrophins have been examined most extensively in studies of the sensory and sympathetic neurons of the avian and rodent peripheral nervous

\footnotetext{
From the Division of Neuroscience, Children's Hospital, and the Department of Neurobiology, Harvard Medical School, Boston

RECEIVED MARCH 26, 1997. ACCEPTED IN FINAL FORM JUNE 14, 1997.

Presented in part at the Canadian Congress of Neurological Sciences, St. John's, June 1994. Awarded the André Barbeau Memorial Prize 1994.

Reprint requests to: Azad Bonni, Division of Neuroscience, Children's Hospital, 300
} Longwood Avenue, Boston, Massachusetts 02115 U.S.A. 
systems (PNS). These studies have revealed two principles of neurotrophin biology in the PNS. The development of each specific population of neurons appears to undergo sequential dependence upon distinct neurotrophins, and the various neurotrophins support the survival of distinct but overlapping populations of neurons of the PNS.

NT-3 appears to promote the proliferation of neural crest cells and of sensory and sympathetic neuroblasts as they come to reside in their respective ganglia.? It has been suggested that NT-3 enhances the proliferation of these neuroblasts either by directly increasing their rate of proliferation or by promoting their survival. ${ }^{8}$ Following the early development of the sensory and sympathetic neurons in the PNS, these neurons undergo a subsequent period of target-dependent neuronal survival that depends on limiting amounts of NGF produced by the target tissue of these neurons. In early experiments carried out by LeviMontalcini and Cohen greater than $90 \%$ of the sympathetic neurons were found to disappear in mice injected at birth with an NGF-neutralizing antibody. ${ }^{9}$ The results of these experiments were recently confirmed in mice in which the NGF gene or the gene encoding the NGF receptor TrkA was disrupted by gene targeting. Mice that are NGF-/- or trkA-/- die within the first month of life. ${ }^{10,11}$ Their sympathetic ganglia are essentially absent by 10 days of life. In addition, they lack the small-sized sensory neurons within the dorsal root and trigeminal ganglia that are believed to respond to pain and temperature stimuli.

While NGF supports the survival of the small sensory neurons, in vitro and in vivo evidence indicates that NT-3 promotes the survival of the large sensory neurons of the dorsal root ganglia during the period of target innervation. ${ }^{12-14}$ The phenotype of mice with targeted mutation of the NT-3 or the gene encoding the NT-3 receptor, TrkC, is the neurological movement disorder of "pseudoathetosis" that reflects an impaired sense of position. A remarkable function of BDNF, as revealed in mice in which the BDNF gene was targeted, is to promote the survival of vestibular sensory neurons. ${ }^{13,15}$ BDNF and TrkB are also required for the survival of a group of visceral sensory neurons in the nodose and petrosal ganglia that innervate the carotid body and for the survival of dorsal root ganglia neurons. ${ }^{4}$

NT-4 displays many of the same activities in vitro as BDNF. This is consistent with the idea that TrkB mediates the biological effects of both neurotrophins. However, examination of the NT-4-/- mice suggests that BDNF and NT-4 have distinct physiological roles. ${ }^{4}$ The NT-4-/- mice do not display the abnormalities that are found in the BDNF-/- or trkB-/- mice, except that they have reduced numbers of visceral sensory neurons within the nodose and petrosal ganglia.

\section{Central Nervous System}

The role that the neurotrophins play in the development of the mammalian CNS has been more difficult to ascertain. This has been attributed to the complexity of the innervation pattern of the various neuronal populations within the CNS, the presence of multiple neurotrophins and their receptors within the same region of the CNS, and the possibility that CNS neurons require additional factors for their development. ${ }^{4}$ The CNS neuronal populations that have been examined in detail with regard to their neurotrophin requirement have generally been those that degenerate in human diseases.

When injected into rodent brains, NGF is capable of prevent- ing death of cholinergic neurons of the basal forebrain following their axotomy in the septohippocampal projection. ${ }^{16}$ Injected NGF can also improve the behavioral performance of aging rats, a finding that is correlated with the ability of NGF to reduce the atrophy of the septal cholinergic neurons in these rats. ${ }^{17}$ These data raised the possibility that NGF may control the survival of these neurons during the development of the mammalian brain. However, results from the NGF-/- and trkA-/- mice reveals that this population is normal in size. ${ }^{10,11}$

Recent studies suggest that the neurotrophin NT-3 may promote the differentiation of rat embryonic cerebral cortical or hippocampal precursor cells into neurons. ${ }^{18.19}$ Although in conventional histologic examination the cerebral cortex and hippocampus in mice with targeted mutations of the NT-3 and trkC genes appear to be normal,,$^{13.14}$ a detailed examination of this area of the CNS remains to be carried out. BDNF also appears to regulate the differentiation of cerebral cortical neurons. Examination of the cerebral cortex in BDNF-/- mice has revealed a reduction in the expression of neuropeptide $Y$ (NP-Y) and the calcium binding protein parvalbumin, which are normally found in distinct subsets of cortical interneurons that also express the neurotransmitter $\gamma$-aminobutyric acid (GABA). As the number of GABAergic neurons appears to be normal in these mice, these results suggest that BDNF regulates the phenotype of these neurons. ${ }^{15}$

Prior to the gene knockout experiments, in vitro and in vivo experiments suggested that the neurotrophins BDNF, NT-3 and NT-4 play a role in the regulation of motor neuron survival during CNS development. ${ }^{20-22}$ Although initial examination of the trkB-/- and trkC-/- mice was consistent with this conclusion, reexamination of these animals and analysis of mice deficient in both BDNF and NT-4 has apparently failed to reveal such abnormalities, leaving the quest open for the motor neuron neurotrophic factor. ${ }^{4}$ Although the known neurotrophins may not be the physiological motor neuron trophic factor, their ability to reduce motor neuron loss in animal models of motor neuron degeneration has raised interest in the possibility that these agents may be used in the treatment of motor neuron diseases such as amyotrophic lateral sclerosis.

\section{Molecular Mechanisms of Neurotrophin ACtion}

The diversity of the biological effects that a given neurotrophic factor exerts on neurons raises questions about the nature of the intracellular mechanisms that transduce the neurotrophic factor signal and that ultimately lead to the multiple phenotypic effects of the neurotrophic factor. Neurotrophin receptor proteins have been identified on responsive neurons, and biochemical events that occur subsequent to receptor activation have been characterized. One set of biochemical changes that is believed to be critical for many of the neuronal responses to these agents consists of alterations in gene expression. Understanding the nature of the pathways by which the neurotrophic factor signal is transduced from its receptor to the nucleus may therefore provide insight into how the neurotrophins trigger specific cellular responses.

Early investigations into the binding properties of NGF on responsive peripheral neurons revealed that these cells express two receptor populations. ${ }^{23}$ NGF bound to some sites with high affinity $\left(\mathrm{K}_{\mathrm{D}}=1 \times 10^{-11}\right)$ and slow dissociation rates and to other sites with low affinity $\left(K_{D}=1 \times 10^{-9}\right)$ and fast dissociation rates. 
Nearly a decade later, an NGF receptor of about $75 \mathrm{kDa}$ that is currently termed p75 was molecularly cloned. ${ }^{24-26}$ At the time that p75 was cloned, this receptor defined a new family of proteins that is now known to include proteins, such as CD40, Fas and the tumor necrosis factor $\alpha$ (TNF- $\alpha$ ) receptors, that are predominantly expressed by immune cells. ${ }^{27}$ In addition to NGF, other neurotrophins can also bind to p 75 with similar affinity kinetics as $\mathrm{NGF}^{28}$

More recently, the trk proto-oncogene has been shown to encode a second receptor for NGF. ${ }^{29-31}$ Other proteins with structural similarity to Trk (currently referred to as TrkA) such as TrkB and TrkC have been characterized. The Trk proteins bind to the neurotrophins with relatively high affinity and overlapping specificity, such that TrkA binds to NGF, TrkB binds to BDNF and NT-4, and TrkC binds to NT-3. ${ }^{4}$ The three Trk receptors display extensive structural similarities with $66 \%$ identity in the primary amino acid sequence. ${ }^{28}$ They all have three immunoglobulin-like domains and a cysteine-rich domain in their extracellular regions. Within the intracellular region, the Trks all contain a tyrosine kinase domain which places these proteins in the superfamily of receptor tyrosine kinases (RTKs) that includes receptors for growth factors such as epidermal growth factor (EGF) and platelet-derived growth factor (PDGF).

Current understanding of the mechanisms by which neurotrophins elicit responses in neurons has come in large part from studies of NGF action on the pheochromocytoma cell line $\mathrm{PC} 12 .{ }^{32.33}$ Upon exposure to NGF, PCl2 cells differentiate into sympathetic neuron-like cells. The NGF-induced differentiation of PC 2 cells results from the interaction of NGF with its receptor, TrkA, and from the intracellular biochemical events that occur subsequent to receptor activation. ${ }^{34,35}$ The $\mathrm{PC} 12$ cell system also serves to highlight the contrast in the biological outcomes that can result from the activation of different RTKs. Whereas NGF triggers the differentiation of PC12 cells into sympathetic neuron-like cells, the growth factor EGF, whose receptor also contains intrinsic tyrosine kinase activity, promotes the proliferation of $\mathrm{PC} 12$ cells. ${ }^{33}$ It is likely that the differences between the NGF- and EGF-induced signaling pathways become apparent in the nucleus, since NGF-induced changes in gene expression are critical for the differentiation response of $\mathrm{PC} 12$ cells. ${ }^{32}$

\section{Trk Receptor Activation}

The TrkA receptor appears to be necessary and sufficient to mediate the biological effects of NGF. PCl 2 cells that lack functional TrkA (nnr5 cells) do not undergo a differentiation response when exposed to NGF. However, TrkA when expressed in nnr5 cells restores NGF responsiveness to these cells.$^{34}$ In addition, the similar phenotype of trkA-/- and NGF-/mice suggests that TrkA is likely to be the functional receptor for NGF in vivo. ${ }^{6}$

The first step in Trk receptor activation is its dimerization, which is effected by the binding of its cognate neurotrophin (Figure 1). The solved structure of the NGF crystal together with the identification of amino acids in the NGF molecule that are required for efficient and specific binding to TrkA have led to a model of NGF-TrkA interaction. ${ }^{28,36}$ Within the NGF dimer, each NGF protomer associates with the other along its long axis. Therefore, the NGF dimer exhibits two-fold symmetry. The amino acids that contribute to TrkA binding appear to be grouped along one side of the NGF dimer and to be derived from both protomers. The binding region of NGF is parallel to the axis of symmetry of the NGF dimer. Therefore, each NGF dimer contains two identical TrkA binding regions that are on opposite sides of the dimer. This may promote the binding of an NGF dimer to two TrkA molecules, thereby effecting receptor dimerization and activation.

The activation of the TrkA receptor protein is manifest in the induction of its kinase activity resulting in TrkA autophosphorylation on tyrosine residues..$^{29-31}$ It appears that dimerization of the receptor triggers the kinase within each TrkA molecule to transphosphorylate tyrosine residues on the other TrkA molecule within the receptor dimer. ${ }^{37}$

Once the TrkA receptor becomes autophosphorylated on tyrosine residues, the phosphorylated tyrosines act as docking sites for intracellular signaling proteins. A characteristic of these signaling proteins is that they contain modular domains that are capable of interacting with proteins that contain a phosphorylated tyrosine. Two types of phosphotyrosine interacting protein modules have been defined, the Src homology 2 module (SH2) and the protein tyrosine binding domain (PTB) ${ }^{38-40}$ The SH2 domain is about one hundred amino acids in length and is found in a variety of signaling proteins that include protein and lipid kinases, phospholipases, phosphatases, and adaptor proteins that lack enzymatic activity. Different SH2 domains have been found to bind to distinct phosphotyrosine peptides. The specificity of these interactions appears to be determined by the sequence of the amino acids that are found immediately C-terminal to the phosphotyrosine residue. ${ }^{41}$ The PTB domain has been recently defined as another phosphotyrosine interacting domain that is found in signaling proteins such as Shc and the insulin receptor substrate protein IRS-140. In contrast to the SH2 domain, the specificity of the PTB-phosphotyrosine binding appears to be determined by the sequence of amino acids that are found $\mathrm{N}$-terminal to the phosphotyrosine.

Phosphorylated TrkA can interact with the proteins phospholipase $\mathrm{C} \gamma$ (PLC $\gamma$ ) and the regulatory (p85) subunit of the phosphatidylinositol 3 kinase (PI-3K) via their SH2 domains. ${ }^{42,43}$ The adaptor protein Shc appears to interact with phosphorylated TrkA via its PTB domain. ${ }^{40}$ Once these proteins bind to the TrkA receptor, they become activated either by phosphorylation or due to a conformational change. Once activated the TrkAassociated proteins transmit signals to effector proteins and thus propagate the NGF signal. What follows these initial signaling events is an array of partly parallel and partly interconnected signaling pathways that we are now beginning to understand in some detail (Figure 1).

\section{Trk Activation of the Ras-MAPK Signaling Pathway}

The GTP-binding protein Ras is a critical target of the biochemical events that are activated immediately downstream of the TrkA receptor. Indeed, it became evident even before the TrkA receptor was identified that Ras is important for mediating the biological activities of NGF. The expression of a constitutively active form of Ras mimics the differentiation effects of NGF and antibodies to Ras, when microinjected into PC12 cells, block the ability of NGF to trigger the differentiation response..$^{44.45}$ Over the past few years, a flurry of research activity has provided a picture of how NGF and growth factors that act via RTKs activate Ras. In the case of TrkA, the recruitment 


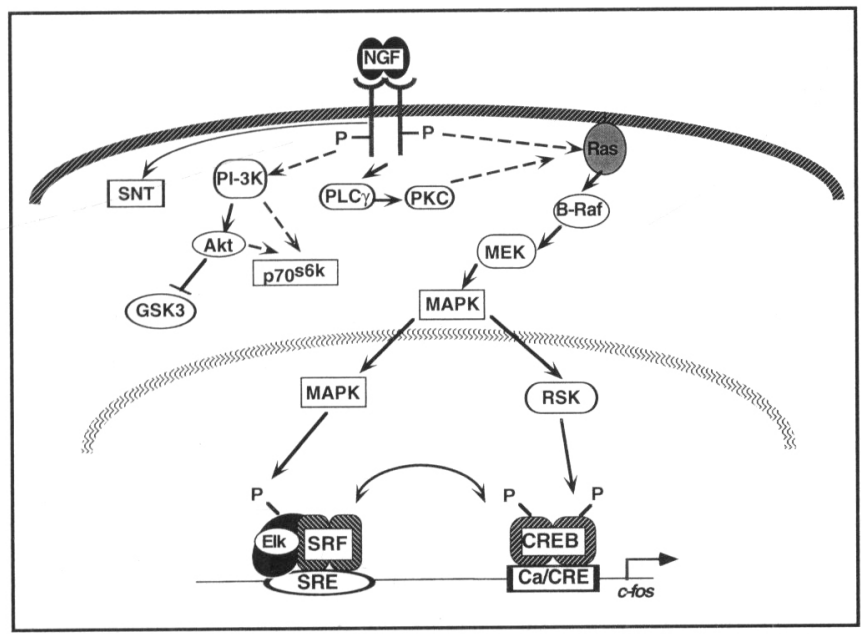

Figure 1: Neurotrophin-induced signaling pathways. A model of the mechanisms that propagate the NGF signal from the plasma membrane to the nucleus. NGF binds to its receptor TrkA inducing its dimerization and tyrosine kinase activity. The tyrosine phosphorylated TrkA binds to Shc (not shown) and activates Ras through a series of protein-protein interactions, described in detail in the text. The activation of Ras may also occur via the PLCY-protein kinase $C$ signaling pathway. Activated Ras then binds the protein kinase B-Raf and activates a protein kinase cascade that culminates in the activation of the protein kinase MAPK. Activated MAPK translocates to the nucleus and catalyzes the phosphorylation of Elk at sites that enhance the ability of Elk to activate transcription. Activated MAPK also stimulates the activity of Rsk2, which induces the phosphorylation of CREB thus promoting CREB cooperativity with the SRE binding proteins leading to the induction of c-fos transcription. The TrkA protein activates other signals, such as the SNT protein and the PI-3K-Akt signaling pathway, that ultimately lead to alterations in gene expression. Neurotrophin-induced signaling pathways in addition to those shown here, such as the JNK and p75 signaling pathways, are discussed in the text.

of Shc and PLC $\gamma$ to TrkA appears to be critical for NGF activation of Ras. ${ }^{42,46}$

Once Shc associates with TrkA via phosphorylated Tyrosine 490 of TrkA, Shc is believed to become a substrate for the TrkA tyrosine kinase. Thus, NGF induces the tyrosine phosphorylation of Shc. That the Shc protein is important in mediating the biological activities of NGF is suggested by the finding that overexpressed Shc protein promotes neurite outgrowth in $\mathrm{PC} 12$ cells in the absence of NGF treatment ${ }^{47}$ The phosphorylation of Shc on tyrosine is critical in this process and is believed to provide a docking site for the adaptor protein Grb2, which associates with Shc by virtue of the interaction of its $\mathrm{SH} 2$ domain with the phosphotyrosine on Shc. ${ }^{48} \mathrm{Grb} 2$ also contains another protein-protein interaction module termed the SH3 domain (Src homology 3), which has been shown to interact with prolinerich peptide ligands. ${ }^{39}$ The protein Sos contains such a peptide that allows it to interact constitutively with Grb2. Therefore, the tyrosine phosphorylation of She triggers its association with a complex that contains Grb2 and Sos. It is believed that this interaction brings the enzyme Sos near the membrane, the site of its substrate Ras. Sos is an exchange factor for the Ras protein, exchanging the bound GDP on the inactive Ras-GDP to Ras-GTP, which leads to the activation of Ras. ${ }^{49}$ Thus the sequence of events described above suggest a simple model where a critical event in linking the activation of TrkA to Ras appears to be the translocation of the enzyme Sos to its site of action at the plasma membrane.

Together with the advances in identifying mechanisms by which Ras is regulated by signals from RTKs, investigations into the biochemical events that occur subsequent to Ras activation led to the identification of a protein kinase cascade that is initiated by Ras. NGF has been found to trigger the activity of a number of serine/threonine kinases including Raf, protein kinase $\mathrm{C}$, and the mitogen-activated protein kinase (MAP kinase). Ras appears to play a critical role in activating Raf and MAP kinase..$^{50,51}$ GTP-bound Ras physically associates with Raf, leading to its activation. ${ }^{49}$ The association of $R$ as with $R$ af is believed to bring Raf to the region near the plasma membrane. This was demonstrated in experiments in which a requirement for Ras in growth factor activation of Raf was bypassed by recruiting Raf to the plasma membrane via fusion of the membrane localizing sequence of Ras CAAX to Raf.$^{52}$ Once Raf is recruited to the plasma membrane, a second critical event is believed to occur that then stimulates the catalytic activity of Raf. The activation of Raf might occur via the tyrosine phosphorylation of Raf on two sites by the nonreceptor tyrosine kinase Src. ${ }^{53}$

Once Raf becomes activated, it catalyzes the phosphorylation of MAP kinase kinase (MAPKK) at two serines, Serine 217 and 221 , leading to its activation. ${ }^{54}$ MAPKK is also referred to as MKK or MEK (for MAP kinase/ERK kinase). MAPKK appears to be a critical mediator of the biological activities of NGF in $\mathrm{PC} 12$ cells, as constitutively activated forms of this kinase mimic the neuritogenic effects of NGF, and the expression of a dominant interferring form of MAPKK represses the ability of NGF to induce neurite outgrowth. ${ }^{55}$ MAPKK is a dual specificity kinase that catalyzes the phosphorylation of MAP kinase on Threonine 183 and Tyrosine $185 .^{56}$

A number of vertebrate MAP kinases have been identified, which range in size from 40 to $64 \mathrm{kDa}$. MAP kinases are also termed extracellular regulated kinases (ERKs) ${ }^{57.58}$ They are proline-directed kinases that phosphorylate their substrates at serines or threonines. One substrate for MAP kinase is the protein kinase $\mathrm{pp} 90^{\mathrm{RSK}}$. This protein kinase was originally identified based on its ability to phosphorylate ribosomal S6 protein in vitro suggesting that $\mathrm{pp} 90^{\mathrm{RSK}}$ may regulate protein translation. However, it now appears that the translational machinery is not a physiological target of this kinase. An important finding in the regulation of MAP kinase and its substrate $\mathrm{pp} 90^{\mathrm{RSK}}$ was the observation that RTKs trigger the translocation of these kinases from the cytoplasm to the nucleus ${ }^{59}$ This suggests that the RasMAP kinase protein kinase cascade culminates in the activation of proteins that may be important in the propagation of the RTK signal to the nucleus to induce changes in gene expression.

\section{NGF-induced Changes in Gene Expression}

A target of the NGF-induced signaling pathways that are activated downstream of TrkA is the nucleus. NGF-induced changes in gene expression appear to be critical for many of its biological activities including neurite outgrowth in PC12 cells. ${ }^{60}$ It has long been expected that the investigation of the mechanism by which NGF-induced changes in gene expression will help our understanding of how the specificity of the NGF signal is maintained as it propagated from the plasma membrane across the cytoplasm. In this regard, it is particularly important 
to compare the effects of TrkA activation on gene expression with those of another RTK, the mitogenic EGF receptor. EGF receptor activation in $\mathrm{PC} 12$ cells triggers many of the same signaling events as TrkA, including the activation of the Ras-MAP kinase pathway, but leads to a mitogenic cellular response ${ }^{61}$ rather than a differentiation response.

\section{Immediate Early Genes and Late Response Genes}

NGF is known to induce the expression of a large number of genes in PC12 cells. These genes have been classified in two major groups, termed the immediate early genes (IEGs) and the late response genes (LRGs). The induction of IEG expression occurs within minutes of NGF treatment. ${ }^{62-64}$ Many of these IEGs encode transcription factors that include the Fos, Jun, Zif268 (or NGFIA), and Nur77 (or NGFIB) families of proteins. ${ }^{64}$ The products of these NGF-induced IEGs bind to promoter sequences within LRGs and consequently regulate LRG expression. The induction of LRG expression occurs typically within hours of NGF treatment.

A variety of NGF-induced LRGs have been identified in PC1 2 cells. NGF-induced LRGs encode proteins that contribute to the neuronal properties $\mathrm{PCl} 2$ cells acquire upon exposure to NGF including the extension of neurites, neurotransmitter synthesis, and the ability to generate $\mathrm{Na}^{+}$-based action potentials. ${ }^{33}$ For example, the induction of the protease transin and the intermediate filament protein peripherin might play a role in neurite outgrowth. The tyrosine hydroxylase gene encoding the rate limiting enzyme in noradrenergic transmitter biosynthesis is also induced with delayed kinetics by NGF. NGF also induces the expression of the peripheral sodium channel proteins PNI and PNII, which endow PC12 cells with the ability to respond to depolarizing stimuli with the generation of action potentials. Although a common set of IEGs appears to be activated by NGF and EGF, the induction of some LRGs appears to be ligand-specific. Thus, within the set of NGF-induced LRGs, many are activated by NGF but not EGF.

\section{The c-fos Proto-oncogene}

The best characterized IEG encodes the transcription factor Fos. The Fos protein is a member of the superfamily of transcription factors that contain the basic leucine zipper (bZIP) motif. The basic region of the protein mediates binding to DNA; the leucine zipper mediates dimerization with other proteins. A heterodimer containing Fos and another leucine zipper containing transcription factor, Jun, binds to the consensus sequence TGAGTCA that is found within 5 ' regulatory regions of many genes including the LRGs. ${ }^{65}$ Whether the Fos protein contributes to the biological activities of NGF and other neurotrophins in the developing or mature nervous system is unknown. The $c$-fos gene has been disrupted in mice by gene targeting. ${ }^{66}$ However, a detailed examination of the nervous system with a view toward the actions of the neurotrophins remains to be carried out.

A wide variety of extracellular stimuli have been shown to induce the expression of the $c$-fos gene in neuronal and nonneuronal cells. ${ }^{63,67}$ Consequently, the regulation of $c$-fos expression has been studied in some detail and has provided a useful model for investigating the mechanisms by which a particular signal, such as the NGF signal, is coupled to changes in gene expression. Although extracellular ligand regulation of $c$-fos expression could occur at several levels from transcriptional initiation to the regulation of Fos protein activity, the regulation of transcriptional activation has been studied in greatest detail. NGF induces the expression of the $c$-fos gene at the transcriptional level in a rapid, robust and transient manner. Importantly, it appears that NGF induction of $c$-fos transcription occurs in the presence of protein synthesis inhibitors suggesting that this induction occurs independently of new protein synthesis. ${ }^{62,68}$ The implication of this finding is that a preexisting cellular machinery mediates the NGF-induced expression of $c$-fos and that this might involve posttranslational modifications of proteins that bind to the $5^{\prime}$ regulatory sequences of the $c$-fos gene.

The $c$-fos promoter has been dissected in many studies over the past decade and a number of major regulatory sequences have been characterized. These include the serum response element (SRE), the calcium response element (CaRE), the Fos API site (FAP) and the sis-inducible element (SIE) that are found respectively at $-300,-60,-290$, and -340 nucleotides upstream of the $c$-fos transcriptional start site. The CaRE is also known as a cyclic AMP response element (CRE). ${ }^{69-74}$

\section{The Role of SRE Binding Proteins in Mediating NGF-induced Transcription}

The SRE was first identified as a promoter element that is critical for serum and growth factor induction of $c$-fos transcription in fibroblast cell lines. ${ }^{75}$ Deletion analysis of the $c$-fos promoter revealed that the SRE is also required for NGF induction of $c$-fos transcription. ${ }^{71}$ The SRE is a 20 bp sequence with dyad symmetry that has been shown to bind to many proteins. Two of these proteins, the serum response factor (SRF) and $\mathrm{p} 62^{\text {TERNARY COMPLEX FACTOR }}$ ( $\mathrm{p} 62^{\mathrm{TCF}}$ ), have been studied extensively. The SRF protein binds as a dimer to the consensus sequence $\mathrm{CC}(\mathrm{A} / \mathrm{T})_{6} \mathrm{GG}$ that is found within the inner core of the SRE. ${ }^{76}$ The SRF binding site has been shown to be critical for the ability of the SRE to mediate $c$-fos transcription in cells exposed to serum, growth factors and NGF. ${ }^{77-80}$

The mechanism by which SRF activates transcription has been studied most extensively in serum stimulated fibroblast cell lines. SRF has been shown to undergo a rapid phosphorylation event in response to serum that appears to enhance the ability of SRF to bind to the SRE in vitro. ${ }^{81}$ However, an in vivo role for this phosphorylation event remains to be determined. Interestingly, one of the kinases that may potentially mediate this event in vivo is $\mathrm{pp} 90^{\mathrm{RSK}}$, which would make SRF a direct target of the Ras-MAP kinase pathway. Although this might be the case for serum in fibroblast cells, it appears that SRF does not undergo the Serine 103 phosphorylation in PC12 cells upon exposure to the purified polypeptide factors NGF and EGF. ${ }^{82}$

In addition to activating transcription directly, it is now widely accepted that a primary function of SRF is to recruit other transcription factors to the SRE that in turn activate transcription. p62 ${ }^{\mathrm{TCF}}$ is a protein that is recruited to the SRE by SRF and binds to the sequence CAGGAT within the 5' region of the SRE. ${ }^{75}$ The $\mathrm{p} 62^{\mathrm{TCF}}$ binding site is critical for growth factor and NGF induction of $c$-fos transcription..$^{75,80}$ Several proteins have been cloned that exhibit the properties of $\mathrm{p} 62^{\mathrm{TCF}}$. These proteins include the SRF accessory factors SAP 1 and 2, and Elk. ${ }^{83,84}$

Accumulating evidence suggests that $\mathrm{p} 62^{\mathrm{TCF}}$ constitutes an important target of the Ras-MAP kinase pathway. ${ }^{85-87}$ Growth factor or NGF treatment of responsive cells triggers the phosphorylation of Elk, an event that is mediated by MAPK. 
Although the phosphorylation of Elk occurs on multiple serines within the C-terminal domain of Elk, the phosphorylation of Serine 383 and 389 is particularly critical for the ability of Elk to mediate growth factor and NGF-induced transcription. ${ }^{82,86}$ The ability of Elk to bind to the SRE and form a ternary complex with SRF might be enhanced by the phosphorylation of Elk. ${ }^{85}$ However, the effect on DNA binding has not been reproduced in other studies. ${ }^{86}$ Elk phosphorylation stimulates the transactivation potential of Elk when it is bound to DNA via the DNA binding domain of a heterologous protein suggesting that the phosphorylation event affects the transactivation potential of Elk directly.

Several other proteins have been identified that bind to the SRE independently of SRF but their roles in mediating SREmediated transcription have not been fully characterized. Proteins that bind to the 3' region of the SRE do not appear to play a critical role in mediating NGF-induced transcription via the SRE. ${ }^{80}$ The role of other SRE-binding proteins in NGFinduced transcription remains to be explored. In addition to p62 ${ }^{\mathrm{TCF}}$, the transcription factor YY1 binds to the 5' region of the SRE. ${ }^{88-90}$ The SRF and YY1 binding sites overlap. Although initial evidence suggested that SRF and YY1 bind to the SRE antagonistically, ${ }^{91}$ a more recent study suggested that YYI facilitates the binding of SRF to the SRE. ${ }^{92}$ Thus, YYl might enhance SRE mediated transcription. The homeodomain protein Phoxl has been found to bind to the inner core of the SRE. ${ }^{93}$ The sequence requirements within the SRE for Phox l, however, are distinct but overlapping with those for SRF and comprise the AT rich inner core. Phox 1 enhances the binding of $\mathrm{SRF}$ to the SRE in vitro. This has been correlated with the ability of Phox I to enhance SRF mediated transcription in vivo.

\section{Cyclic AMP Response Element Binding Protein}

Although the SRE is essential for growth factor and NGF induction of $c$-fos transcription, other sites within the $c$-fos promoter contribute to the growth factor and NGF response..$^{74,80,94}$ These sites include the CaRE, FAP and SIE promoter elements, each of which can function as a cyclic AMP response element (CRE) by activating transcription in response to stimuli that elevate the intracellular levels of cyclic AMP. ${ }^{74.95}$ The CaRE can also induce $c$-fos transcription in response to stimuli, such as membrane depolarization, that elevate the intracellular levels of calcium. $^{71}$

The CREs mediate NGF-induced $c$-fos transcription at least in part by their ability to bind the transcription factor cyclic AMP response element binding protein (CREB).$^{80.94}$ Like Fos, CREB is a member of the bZIP superfamily of transcription factors. ${ }^{96,97}$ CREB was first identified as a transcription factor that mediates cyclic AMP-induced transcription. However, subsequent experiments revealed that $\mathrm{CREB}$ can also mediate calcium-induced transcription. ${ }^{98}$ Agents that stimulate a rise in the intracellular levels of cyclic AMP or calcium induce the phosphorylation of CREB at the identical key regulatory site, Serine 133 , that is critical for the CREB-mediated transcriptional response to these stimuli. ${ }^{98,99}$ The c-AMP-induced CREB phosphorylation is mediated by the cAMP-dependent protein kinase (PKA). In response to calcium signals, a calcium-calmodulindependent kinase (CaMK) is believed to catalyze the CREB Serine 133 phosphorylation.

As with agents that increase the intracellular levels of cyclic
AMP or calcium, growth factors and NGF also induce the phosphorylation of CREB at Serine 133. The inducible Serine 133 phosphorylation is critical for the ability of CREB to mediate NGF-induced $c$-fos transcription. ${ }^{94}$ However, the NGF-induced CREB phosphorylation appears to be catalyzed by Rsk2, a member of the pp90 ${ }^{\text {RSK }}$ family. ${ }^{100}$ NGF activation of Rsk2 occurs via the Ras-MAPK signaling pathway. Thus, distinct signaling pathways mediate CREB activation in response to NGF, growth factors, cyclic AMP and calcium signals.

Once phosphorylated in response to NGF, growth factors, calcium or cyclic AMP signals, CREB appears to mediate transcription via distinct mechanisms depending on the nature of the initial stimulus. ${ }^{80}$ In response to calcium or cyclic AMP signals, CREB can activate transcription independently of other promoter-bound transcription factors. By contrast, to confer NGFinduced transcription, CREB activates transcription via a mechanism that requires a cooperative interaction with other promoter-bound transcription factors, such as SRF, bound at the $c$-fos promoter. The presence of CREs within the promoters of other NGF-induced IEGs suggests that CREB cooperativity with other transcription factors is a mechanism that might be generally employed by cells to couple the NGF signal to IEG transcription.

The mechanism by which the Serine 133 phosphorylation facilitates the ability of CREB to activate transcription appears to be an increase in the transactivation potential of CREB. A protein referred to as CREB binding protein (CBP) has been identified that binds to CREB when CREB is phosphorylated at Serine $133 .^{101} \mathrm{CBP}$ is a transcriptional coactivator; it does not bind to DNA directly but contacts sequence-specific transcription factors and subsequently activates transcription. CBP might recruit the RNA polymerase complex by virtue of its ability to associate with the general transcription factor TFIIB. ${ }^{102}$ The importance of CBP in NGF-induced signaling remains to be determined.

\section{The Generation of Signal Specificity Within the Ras-MAP Kinase Pathway}

The identification of the Ras-MAP kinase signaling pathway as a major route for the NGF signal to proceed from the plasma membrane to the nucleus raised the question of how the cell deciphers signals that arise from similarly structured RTKs that all activate the Ras-MAP kinase pathway. For example, in $\mathrm{PC} 12$ cells the Ras-MAP kinase pathway is activated in response to both NGF and EGF. However, the phenotypic responses of PC 12 cells to these agents are quite distinct: NGF enhances the differentiation of these cells into neuron-like cells, whereas EGF promotes their continued proliferation.

It is now believed that the kinetics of the activation of the Ras-MAP kinase pathway may be important in determining the type of biological response that results. ${ }^{58}$ Specifically, in $\mathrm{PC} 12$ cells the rapid but transient activation of this signaling pathway in response to EGF contrasts with the rapid but prolonged kinetics of activation upon exposure to NGF. How this difference in the kinetics of the Ras-MAP kinase cascade is generated is unclear but it appears to arise at the level of receptor phosphorylation.

Recent experiments suggest that CREB contributes to the readout of differences in the kinetics of activation of the RasMAP kinase signaling pathway (Figure 2). CREB transforms 
the differences in the kinetics of the activation of the Ras-MAP kinase pathway into qualitative differences in gene expression owing to the requirement for cooperativity in its transcriptional response to growth factor and NGF signals. The presence of CREs within the promoters of NGF-responsive LRGs suggests that CREB contributes directly to the expression of NGFinduced LRGs. ${ }^{80}$ The prolonged activation of CREB in NGF treated cells might facilitate its interaction with the products of the IEGs at the promoter of NGF-responsive LRGs leading to their induction. Although EGF and NGF might induce identical IEGs, at later time points CREB is no longer activated in EGF treated cells leading to a failure of induction of NGF-specific LRGs. At earlier time points, the absence of IEG products results similarly in the failure of EGF activated CREB to stimulate transcription of the LRGs.

Recent results from a number of laboratories support the model wherein quantitative differences in the Ras-MAP kinase pathway account for qualitative differences in transcriptional responses to distinct agents. ${ }^{58}$ For example, increasing the amplitude of EGF receptor tyrosine kinase activity by overexpression of the EGF receptor in $\mathrm{PC} 12$ cells induces a differentiation response to EGF. ${ }^{103}$ This correlates with the sustained activation of MAP kinase in these cells in response to EGF. Still, more experiments are required to validate the model that is proposed in Figure 2. For example, it will be important to demonstrate that the prolonged activation of CREB in NGF treated cells facilitates its cooperation with products of the IEGs at promoters of the NGF-responsive LRGs.

\section{RAS-MAP Kinase Independent Mechanisms of NGF- activated Transcription}

Although our studies have focused on mechanisms of NGFactivated $c$-fos transcription that occur via the Ras-MAP kinase pathway, recent evidence suggests that other signaling pathways will also likely be significant in transducing the NGF signal to the nucleus.

\section{PI-3K Signaling}

As described earlier, the induction of TrkA autophosphorylation by NGF triggers the association of a number of proteins with the receptor. The association of two proteins, the adaptor protein Shc and the enzyme PLC $\gamma$, appears to be important for the activation of Ras. ${ }^{42,46}$ In contrast, despite evidence that PI$3 \mathrm{~K}$ might be capable of activating the Ras protein, the association and activation of PI-3K does not appear to be critical for NGF activation of Ras. ${ }^{42,46,104}$ This raises the question of the role PI-3K activation in NGF signaling. Recent findings suggest that PI-3K activation might be particularly important for the survival promoting actions of NGF. ${ }^{105}$

Although the association of the regulatory subunit of PI-3K, $\mathrm{p} 85$, with TrkA is debated, NGF activation of PI-3K activity has been a reproducible finding. Association of $\mathrm{p} 85$ with TrkA triggers the tyrosine phosphorylation of $\mathrm{p} 85$ but the mechanism by which this phosphorylation stimulates the activity of the PI- $3 \mathrm{~K}$ enzyme is unclear. It might induce a conformational alteration in the p110 catalytic subunit. ${ }^{39}$ Once activated, PI-3K induces the phosphorylation of phosphatidylinositol leading to the production of PI-3,4$\mathrm{P}_{2}{ }^{106.107} \mathrm{PI}-3,4-\mathrm{P}_{2}$ has been shown to stimulate the activity of a kinase that is the product of the proto-oncogene Akt. ${ }^{108,109}$ Recent results suggest that Akt mediates the survival promoting effects of PI3K activation. ${ }^{110}$ The physiological substrates of Akt that promote neuronal survival remain to be determined.

Another kinase that appears to be activated downstream of PI-3K is the kinase pp70S6K. ${ }^{111}$ Inhibition of PI-3K by the drug wortmannin inhibits the ability of growth factors to activate pp70S6K. Importantly, the activation of this kinase might be one way by which the PI-3K signal is transduced to the nucleus. In fibroblasts, serum can trigger the phosphorylation of the protein CREM, a CREB-related protein, at a site that is equivalent to CREB Serine 133 via the kinase pp70S6K. ${ }^{112}$ Although this kinase is not likely to mediate the NGF-induced phosphorylation of CREB Serine 133 in PC1 2 cells, ${ }^{94}$ it will be interesting to determine if $\mathrm{pp} 70^{\mathrm{S} 6 \mathrm{~K}}$ stimulates CREB phosphorylation in other cells or in response to other neurotrophins and purified polypeptide growth factors such as PDGF.

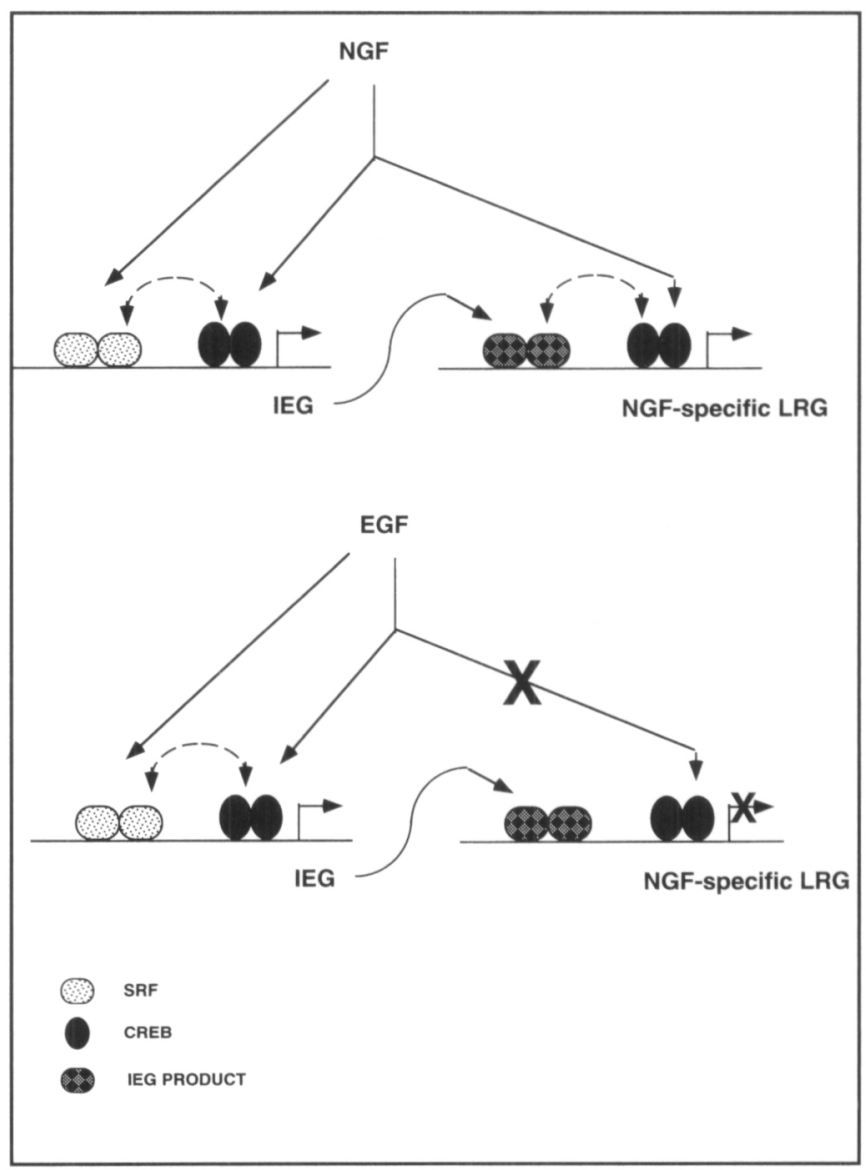

Figure 2: A model of how specificity of neurotrophin responses is generated by the Ras-MAPK signaling pathway. Differential kinetics of $C R E B$ activation and a requirement for CREB cooperativity in CREBmediated transcriptional responses to RTKs confer specificity to neurotrophin-induced gene expression. NGF- and EGF-activated CREB stimulates the expression of IEGs by cooperating with other promoterbound transcription factors. In the case of the c-fos gene, CREB cooperates with the SRE-binding proteins. The prolonged phosphorylation of CREB may facilitate its cooperativity with the products of the IEGs at the promoters of NGF-responsive genes. If the activation of NGFresponsive genes is dependent on CREB cooperativity with the products of the IEGs, the transient phosphorylation and activation of CREB in $E G F$ treated cells explains the failure of EGF to activate NGF-responsive genes. 


\section{NGF Activation of SNT}

A mechanism by which specificity in signaling is imparted to the TrkA differentiation signal, as compared to RTK signals that are mitogenic, might result from the generation of a specific signal downstream of TrkA. In this regard, NGF but not EGF triggers the phosphorylation of a protein, termed SNT, that was identified based on its ability to associate with the protein p13sucl. ${ }^{113}$ SNT has been purified, and peptide sequences suggest that it is a novel protein. The tyrosine phosphorylation of SNT has been shown to occur in response to neurotrophins but not EGF. Interestingly, in PC12 cells basic FGF also induces the tyrosine phosphorylation of SNT which correlates with the ability of this agent to trigger a differentiation response in these cells.

The mechanism by which SNT becomes activated in response to NGF has been recently investigated. A sequence within the membrane proximal region of TrkA appears to be critical for the NGF activation of SNT. ${ }^{114}$ This region of TrkA contains the sequence KFG that is also found in other Trks but not in the EGF receptor. Importantly, deletion of this region within TrkA not only blocked the activation of SNT but also impaired the ability of NGF to induce a differentiation response. However, the ability of NGF to enhance the survival of PC12 cells was not affected. Moreover, NGF activation of the RasMAP kinase pathway was not affected by the KFG mutation of TrkA. Interestingly, the activation of $c$-fos transcription was reduced significantly, suggesting the presence of a Ras-MAP kinase independent mechanism that is critical in the activation of $c$-fos transcription in response to NGF. The transcription factors that couple the KFG-SNT signal to the activation of transcription remain to be determined. Another open question is the mechanism by which the membrane proximal region of TrkA activates SNT. It will also be important to determine how the FGF receptor triggers the tyrosine phosphorylation of SNT.

\section{The Jun N-terminal Kinase Signaling Pathway}

The proline-dependent kinase Jun N-terminal kinase (JNK) was identified based on its ability to phosphorylate Jun on Serines 63 and 73 upon exposure of cells to various stress inducers such as UV radiation. ${ }^{115}$ These phosphorylation events were shown to be important for the ability of Jun to activate transcription in a sequence specific manner. Other targets of JNK include the transcription factors ATF2 and Elk. ${ }^{116.117}$ JNK appears to be activated by a protein kinase cascade that resembles the Ras-MAP kinase cascade. ${ }^{118}$ Thus, current evidence suggests that the Ras-related GTPase proteins Rac and CDC42 activate the protein kinases MEKK 1 and 2. These kinases in turn activate the kinase MKK (or MEK) 3 and 4, which in turn activate the kinase JNK. Another kinase that is activated by MKK 3 is the p38 kinase. The magnitude of growth factor activation of components of these pathways appears to be much less than that in response to stress-inducing stimuli. Although evidence has been presented to suggest that NGF might activate this signaling pathway, recent work reveals that the withdrawal of NGF from cells that are dependent on NGF for survival also appears to activate the Jun kinase signaling pathway and that components of this pathway mediate the apoptosis that results from NGF withdrawal. ${ }^{119}$

A question that remains to be addressed is the mechanism by which this pathway is activated upstream of the Ras-related pro- teins Rac and CDC42. Recent evidence suggests that a ceramide-initiated JNK signaling pathway mediates stressinduced apoptosis. ${ }^{120}$ Ceramide activates a protein kinase termed ceramide-activated protein kinase (CAPK). ${ }^{121}$ A substrate of CAPK appears to be the kinase Raf. ${ }^{122}$ Taken together, these findings raise the testable possibility that within the JNK signaling pathway, MEKK 1 and 2 might also be targets of CAPK. The relationship between CAPK and the Ras-related proteins is unclear at this point. CAPK might propagate the NGF signal that emanates from the $\mathrm{p} 75$ receptor since $\mathrm{p} 75$ can trigger the activation of the sphingomyelinase pathway leading to the release of ceramide from sphingomyelin. ${ }^{123}$

\section{p75 Signaling}

The role that $\mathrm{p} 75$ plays in mediating the biological effects of neurotrophins has been debated over the years. Initial experiments suggested that the cytoplasmic portion of p75 might mediate the biological effects of NGF in $\mathrm{PCl} 2$ cells. However, its expression in heterologous cell systems did not mediate biological responses to $\mathrm{NGF}^{28}$ The identification of TrkA as a receptor that is necessary and sufficient to trigger the commonly studied NGF effects raised doubts about the role of $\mathrm{p} 75$ in mediating NGF signals. Subsequently, it was suggested that p75 might associate directly with TrkA to form high affinity sites for NGF. However, the absence of biochemical data for a physical association between TrkA and p75 suggests alternative models by which p75 might modulate the binding of NGF to TrkA. For example, p75 might concentrate NGF at the surface of the cell and increase the rate of association of NGF with TrkA. ${ }^{124}$ Although mice with targeted disruption of the p75 gene exhibit few abnormalities, sensory neurons of the trigeminal ganglia exhibit an altered survival dose response to the neurotrophins. ${ }^{125}$ The possibility that p75 might also determine specificity of neurotrophin binding to a particular Trk is an interesting idea that deserves further study. 5

Recently, there has been a surge in interest in p75 signaling as a number of studies have implicated $\mathrm{p} 75$ in promoting cell death independently of TrkA. p75 was found to trigger apoptosis in a neuroblastoma cell line upon the withdrawal of NGF. ${ }^{126}$ The loss of basal forebrain cholinergic neurons that occurs normally in mice postnatally has been found to be mediated by $\mathrm{p} 75$. The basal forebrain cholingergic neurons that are targeted by p75 do not express TrkA and account for $25 \%$ of the population of basal forebrain cholinergic neurons. ${ }^{127}$ The mechanism by which p75 triggers apoptosis in neurons remains to be determined. However, structural similarity within the cytoplasmic domain among p75 and members of the tumor necrosis factor receptor family that includes TNF $\alpha$, CD40 and Fas has been noted. ${ }^{27}$ Interestingly, there appears to be a domain, termed the death domain, within this region of these receptors that bears structural similarity to the Drosophila death-inducing protein Reaper. The death domain within these receptors appears to mediate protein-protein interactions with cytoplasmic proteins that also contain death domains. ${ }^{28}$ Whether these proteins interact with $\mathrm{p} 75$ remains to be determined. The involvement of the JNK pathway in cell death that results from NGF withdrawal suggests that the p75 signal might be relayed to this pathway. It will be interesting to test if this could occur via p75-induced sphingomyelinase and CAPK.

The p75 protein might also elicit cellular responses in addition to apoptosis independently of TrkA. NGF, but not the other 
neurotrophins, activates $\mathrm{NF}_{\mathrm{K}} \mathrm{B}$ signaling in Schwann cells in a p75-dependent manner. The p75-activated $\mathrm{NF}_{\mathrm{K}} \mathrm{B}$ signaling pathway does not lead to cell death and might therefore exert trophic or differentiative effects. ${ }^{129}$

\section{Perspectives}

The pace of research into the mechanisms by which neurotrophins mediate their effects has accelerated over the past few years. The intracellular biochemical pathways that propagate the neurotrophin signals from the plasma membrane to the nucleus in cell lines have thus been increasingly delineated. Much of our understanding about the mechanisms of neurotrophin action has come from studies of NGF-induced signaling. However, it is likely that as the mechanisms by which other neurotrophins mediate their effects are studied in greater detail differences between the intracellular signaling events that are activated by NGF and the other neurotrophins will become apparent. As these signaling pathways are characterized in greater detail, it will be important to determine the mechanisms by which specificity is conferred leading to a particular cellular response. It will also be important to determine the physiologic role of each neurotrophin-induced signaling pathway in the development of the nervous system. This will require the study of signaling pathways in vivo and the use of mice in which genes encoding the various signaling proteins have been disrupted.

In addition to learning about the role of neurotrophin signaling pathways in the normal development of the nervous system, characterization of the neurotrophin-activated signaling mechanisms should provide insights into the pathogenesis of degenerative disorders of the nervous system. Mutation of the CBP and rsk-2 genes have been found to be linked to two hereditary disorders, the Rubinstein-Taybi $i^{130}$ and the Coffin-Lowry ${ }^{131}$ syndromes respectively. Mental retardation and facial and digital dysmorphisms are important features of both of these disorders. It will be important to determine if disruption of neurotrophinactivated signaling contributes to the abnormalities in brain development that are manifest in these disorders. It will also be important to determine if inactivation of genes that encode other proteins that transduce neurotrophin signals to the nucleus underlie other diseases of the nervous system.

The elucidation of the intracellular mechanisms by which neurotrophins promote neuronal survival should also provide a basis for the potential development of novel strategies in the treatment of degenerative disorders of the nervous system. The therapeutic potential of the neurotrophins has been demonstrated in animal models of degenerative and metabolic disorders of the nervous system including models of motor neuron disease and polyneuropathies. However, the neurotrophins have only recently entered the clinical arena. ${ }^{3}$ Controlled clinical trials of the neurotrophins in diseases such as amyotrophic lateral sclerosis and diabetic neuropathy have revealed that the administration of the neurotrophins is often accompanied by adverse effects. To improve the therapeutic index of the neurotrophins, it will be important to gain further understanding of the pharmacokinetics and toxicity of the neurotrophins. In addition, an important goal of the investigations of the neurotrophin-activated signaling mechanisms that enhance neuronal survival is that increased understanding of these mechanisms will provide the rationale for the development of additional therapeutic agents that exhibit the trophic effects of the neurotrophins but that have few adverse effects.

\section{GLOSSARY}

Trk: A family of receptor proteins that contain intrinsic tyrosine kinase activity within their intracellular domain. The Trk family of proteins mediate many of the biological effects of the neurotrophins. Neurotrophin binding to a Trk protein induces the tyrosine kinase activity of the Trk protein leading to autophosphorylation of Trk on tyrosine residues.

SH2 domain: A phosphotyrosine-binding protein domain that is contained within many intracellular signaling proteins. The $\mathrm{SH} 2$ domain mediates the interaction of a particular signaling protein with a second protein via an interaction with a tyrosine-phosphorylated peptide motif within the second protein. The specificity of interaction is achieved by the type of $\mathrm{SH} 2$ domain and by the structure of the phosphopeptide motif.

PTB domain: A protein domain that is contained within intracellular signaling proteins and that mediates interactions with proteins containing a specific phosphotyrosine peptide motif.

Shc: An adaptor signaling protein that contains an SH2 domain and a PTB domain. Once TrkA becomes activated, She binds to TrkA via the PTB domain of Shc and phosphorylated Tyrosine 490 of TrkA. Once bound to TrkA, Shc becomes tyrosine phosphorylated. Grb2: An adaptor signaling protein that contains an $\mathrm{SH} 2$ domain and two SH3 domains. Grb2 is constitutively associated with Sos. Tyrosine phosphorylation of Shc by an activated TrkA allows Grb2 to bind Shc and thus leads to the recruitment of a Grb2-Sos complex to the receptor.

Sos: A GDP/GTP exchange protein for the small GTP binding protein Ras.

PLC $\gamma$ : A phospholipase that hydrolyzes phosphoinositides leading to the production of diacylglycerol and inositol phosphates such as inositol-1,4,5-trisphosphate (IP $)_{3}$.

PI-3K: A lipid kinase that catalyzes the phosphorylation of phosphatidylinositol leading to the production of PI-3,4-P .

Ras: A small GTP-binding protein. GTP-bound Ras binds to and activates the protein kinase Raf.

Raf: A serine/threonine protein kinase. Once activated by Ras, it activates MAPKK or MEK.

MAPKK: A protein kinase with dual specificity. Once activated by Raf, it catalyzes the phosphorylation of MAPK on threonine and tyrosine.

MAPK: Mitogen-activated protein kinase is also referred to as extracellular activated kinase (ERK). Once activated, MAPK translocates to the nucleus where it catalyzes the phosphorylation of transcription factors.

Rsk2: A serine/threonine protein kinase that is activated by MAPK. One of the substrates of Rsk2 is the transcription factor CREB.

SRF: Serum response factor is a transcription factor that binds to the inner core of the serum response element (SRE), a DNA sequence that is located within the promoters of many immediate early genes such as the $c$-fos proto-oncogene.

Elk: A transcription factor that binds to the 5' region of the SRE only when SRF is bound to the SRE. Elk is a substrate for MAPK. Once phosphorylated by MAPK, Elk activates transcription.

CREB: Cyclic AMP response element binding protein is a transcription factor that activates transcription in response to growth factors, neurotrophins, and neutransmitters.

CBP: CREB binding protein associates with Serine 133-phosphorylated CREB and recruits the RNA polymerase complex to the promoter of a gene leading to activation of transcription. CBP acts as a coactivator for other transcription factors in addition to CREB.

$c$-fos: The $c$-fos proto-oncogene is an immediate early gene whose 
protein product encodes a transcription factor. The Fos protein dimerizes with another transcription factor Jun to form the AP1 transcription factor complex, which activates transcription of genes that contain API binding sites within their promoters.

SNT: A tyrosine phosphorylated protein that is activated by NGF but not EGF.

JNK: The Jun N-terminal kinase is a protein kinase that is activated by a variety of stress-inducing agents including UV irradiation and withdrawal of NGF. The c-Jun protein is a substrate of JNK.

p75: The low affinity neurotrophin receptor. The $\mathrm{p} 75$ protein is a member of a family of receptor proteins that includes the TNF receptors.

\section{ACKNOWLEDGEMENTS}

We thank J. Kornhauser, A. Shaywitz, and C. Wong for critical reading of the manuscript and helpful discussions. Support for this review was provided by an NIH ROI grant (CA43855; M. E. G.).

\section{REFERENCES}

1. Levi-Montalcini R. The nerve growth factor 35 years later. Science 1987; 237: 1154-1162.

2. Jelsma TN, Aguayo AJ. Trophic factors. Curr Opin Neurobiol 1994; 4: 717-725.

3. Yuen EC, Mobley WC. Therapeutic potential of neurotrophic factors for neurological disorders. Ann Neurol 1996; 40: 346-354.

4. Ip NY, Yancopoulos GD. The neurotrophins and CNTF: two families of collaborative neurotrophic factors. Ann Rev Neurosci 1996; 19: 491-515.

5. Lewin GR, Barde Y-A. Physiology of the neurotrophins. Ann Rev Neurosci 1996; 19: 289-317.

6. Snider WD. Functions of the neurotrophins during nervous system development: what the knockouts are teaching us. Cell 1994; 77: 627-638.

7. Kalcheim C, Carmeli C, Rosenthal A. Neurotrophin 3 is a mitogen for cultured neural crest cells. Proc Natl Acad USA 1992; 89: $1661-1665$.

8. Dicicco-Bloom E, Friedman WJ, Black IB. NT-3 stimulates sympathetic neuroblast proliferation by promoting precursor survival. Neuron 1993; 11: 1101-1111.

9. Levi-Montalcinin R, Booker B. Destruction of the sympathetic ganglia in mammals by an antiserum to a nerve growth factor protein. Proc Natl Acad Sci USA 1960; 46: 384-391.

10. Crowley C, Spencer SD, Nishimura MC, et al. Mice lacking nerve growth factor display perinatal loss of sensory and sympathetic neurons yet develop basal forebrain cholinergic neurons. Cell 1994; 76: 1001-1012.

11. Smeyne RJ, Klein R, Schnapp A, et al. Severe sensory and sympathetic neuropathies in mice carrying a disrupted trk/NGF receptor gene. Nature 1994; 368: 246-249.

12. Hory-Lee F, Russell M, Lindsay RM, Frank E. Neurotrophin 3 supports the survival of developing muscle sensory neurons in culture. Proc Natl Acad Sci USA 1993; 90: 2613-2617.

13. Ernfors P, Lee K-F, Kucera J, Jaenisch R. Lack of neurotropin-3 leads to deficiencies in the peripheral nervous system and loss of limb proprioceptive afferents. Cell 1994; 77: 503-512.

14. Klein R, Silos-Santiago I, Smeyne RJ, et al. Disruption of the neurotrophin-3 receptor gene trkC eliminates Ia muscle afferents and results in abnormal movements. Nature 1994; 368: 249-251.

15. Jones KR, Farinas I, Backus C, Reichardt LF. Targeted disruption of the brain-derived neurotrophic factor gene perturbs brain and sensory neuron but not motor neuron development. Cell 1994; 76: $989-1000$.

16. Hefti F. Nerve growth factor promotes survival of septal cholinergic neurons after fimbrial transections. J Neurosci 1986; 6: 2155-2162.

17. Fischer W, Wictorin K, Bjorklund A. Amelioration of cholinergic neuron atrophy and spatial memory impairment in aged rats by nerve growth factor. Nature 1987; 326: 65-68.

18. Ghosh A, Greenberg ME. Distinct roles for bFGF and NT-3 in the regulation of cortical neurogenesis. Neuron 1995; 15: 1-20.

19. Vicario-Abejon C, Johe KK, Hazel TG, Collazo D, McKay RDG Functions of basic fibroblast growth factor and neurotrophins in the differentiation of hippocampal neurons. Neuron 1995; 15: 105-114.

20. Sendtner M, Holtmann B, Kolbeck R, Thoenen H, Barde Y-A. Brain-derived neurotrophic factor prevents the death of motoneurons in newborn rats after nerve section. Nature 1992; 360: $757-759$

21. Yan Q, Elliot J, Snider WD. Brain-derived neurotrophic factor rescues spinal motor neurons from axotomy-induced cell death. Nature 1992; 360: 753-755.

22. Henderson CE, Camu W, Mettling C, et al. Neurotrophins promote motor neuron survival and are present in embryonic limb bud. Nature 1993; 363: 266-270.

23. Sutter A, Riopelle RJ, Harris-Warrick RM, Shooter EM. Nerve growth factor receptors. Characterization of two distinct classes of binding sites on chick embryo sensory ganglia cells. J Biol Chem 1978; 82: 5972-5982.

24. Chao MV, Bothwell MA, Ross AH, et al. Gene transfer and molecular cloning of the human NGF receptor. Science 1986; 232: 518-521.

25. Johnson D, Lanahan A, Buck CR, et al. Expression and structure of the human NGF receptor. Cell 1986; 47: 545-554.

26. Radeke MJ, Misko TP, Hsu C, Herzenberg LA, Shooter EM. Gene transfer and molecular cloning of the rat nerve growth factor receptor. Nature 1987; 325: 593-597.

27. Chao MV. Neurotrophin receptors: a window into neuronal differentiation. Neuron 1992b; 9: 583-593.

28. Bothwell M. Functional interactions of neurotrophins and neurotrophin receptors. Ann Rev Neurosci 1995; 18: 223-253.

29. Kaplan DR, Hempstead B, Martin-Zanca D, Chao MV, Parada LF. The trk proto-oncogene product: a signal transducing receptor for nerve growth factor. Science 1991 a; 242: 554-558.

30. Kaplan D, Martain-Zanca D, Parada LF. Tyrosine phosphorylation and tyrosine kinase activity of the trk proto-oncogene product induced by NGF. Nature 1991b; 350: 158-160.

31. Klein R, Jing S, Nanduri V, O'Rourke E, Barbacid M. The trk proto-oncogene encodes a receptor for nerve growth factor. Cell 1991; 65: 189-197.

32. Greene LA, Tischler AS. PCI2 pheochromocytoma cultures in neurobiological research. Adv Cell Neurobiol 1982; 3: 373-414.

33. Halegoua S, Armstrong RC, Kremer NE. Dissecting the mode of action of a neuronal growth factor. Curr Top Microb Immun 1990; 165: 119-170.

34. Loeb D, Maragos J, Martin-Azanca D, Chao MV, Greene LA. The trk proto-oncogene rescues NGF responsiveness in mutant NGFnonresponsive PC12 cell lines. Cell 1991; 66: 961-966.

35. Hempstead BL, Rabin SJ, Kaplan L, et al. Overexpression of the trk tyrosine kinase rapidly accelerates nerve growth factorinduced differentiation. Neuron 1992; 9: 883-896.

36. McDonald NQ, Lapatto R, Murray-Rust J, et al. New protein fold revealed by a $2.3 \mathrm{~A}$ resolution crystal structure of nerve growth factor. Nature 1991; 354:411-414.

37. Heldin C. Dimerization of cell surface receptors in signal transduction. Cell 1995; 1995: 213-223.

38. Koch CA, Anderson D, Moran MF, Ellis C, Pawson T. SH2 and SH3 domains: elements that control interactions of cytoplasmic signaling proteins. Science 1991; 252: 668-674.

39. Cohen GB, Ren R, Baltimore D. Modular binding domains in signal transduction proteins. Cell 1995; 80: 237-248.

40. van der Geer P, Pawson T. The PTB domain: a new protein module implicated in signal transduction. Trends Biochem Sci 1995; 20: 277-280.

41. Songyang Z, Shoelson SE, Chaudhuri M, et al. SH2 domains recognize specific phosphopetide sequences. Cell 1993; 72: 767-778.

42. Obermeier A, Halfter $\mathrm{H}$, Wiesmuller $\mathrm{KH}$, et al. Tyrosine 785 is a major determinant of Trk-substrate interaction. EMBO J 1993a; 12: $933-941$

43. Obermeier A, Lammers R, Wiesmuller K, et al. Identification of trk binding sites for SHC and phosphatidylinositol 3'-kinase and formation of a multimeric signaling complex. J Biol Chem 1993b; 268: 22963-22966. 
44. Bar-Sagi D, Feramisco JR. Microinjection of the ras oncogene protein into PC1 2 cells induces morphologic differentiation. Cell 1985; 42: 841-848.

45. Hagag N, Halegoua $S$, Viola $M$. Inhibition of growth factorinduced differentiation of $\mathrm{PC} 12$ cells by microinjection of antibody to ras p21. Cell 1986; 319:680-682.

46. Stephens RD, Loeb D, Copeland T, et al. Trk receptors use redundant signal transduction pathways involving SHC and PLC gamma 1 to mediate NGF responses. Neuron 1994; 12: 691-705.

47. Rozakis-Adcock M, McGlade J, Mbamulu G, et al. Association of the Shc and Grb2/Sem5 SH2-containing proteins is implicated in activation of the Ras pathway by tyrosine kinases. Nature 1992; 360: 689-692.

48. Lowenstein E, Daly R, Batzer A, et al. The SH2 and SH3 domaincontaining protein GRB2 links receptor tyrosine kinases to ras signalling. Cell 1992; 70: 431-442.

49. McCormick F. Activators and effectors of ras p21 proteins. Curr Opin Genet Devel 1994; 4: 71-76.

50. Thomas SM, DeMarco M, D'Arcangelo G, Holegoua S, Brugge J. Ras is essential for nerve growth factor and phorbol ester induced tyrosine phosphorylation of MAP kinases. Cell 1992; 68: 1031-1040

51. Wood KW, Sarnecki C, Roberts TM, Blenis J. Ras mediates nerve growth factor receptor modulation of three signal-transducing protein kinases: MAP kinase, Raf-1, and RSK. Cell 1992; 68: $1041-1050$

52. Leevers SJ, Paterson HF, Marshall CJ. Requirement for Ras in Raf activation is overcome by targeting Raf to the plasma membrane. Nature 1994; 364: 411-414.

53. Marais R, Light Y, Paterson HF, Marshall CJ. Ras recruits Raf-1 to the plasma membrane for activation by tyrosine phopshorylation. EMBO J 1995; 14: 3136-3145.

54. Alessi DR, Saito Y, Campbell DG, et al. Identification of the sites in MAP kinase kinase-1 phosphorylated by p74raf-1. EMBO J 1994; 13: 1610-1619.

55. Cowley S, Paterson H, Kemp P, Marshall CJ. Activation of MAP kinase kinase is necessary and sufficient for $\mathrm{PC} 12$ cell differentiation and for transformation of NIH 3T3 cells. Cell 1994; 77: 841-852.

56. Marshall CJ. MAP kinase kinase kinase, MAP kinase kinase, and MAP kinase. Curr Opin Genet Devel 1994; 4: 82-89.

57. Blenis J. Signal transduction via the MAP kinases: proceed at your own rsk. Proc Natl Acad Sci. 1993; 90: 5889-5892.

58. Marshall CJ. Specificity of receptor tyrosine kinase signaling: transient versus sustained extracellular signal-regulated kinase activation. Cell 1995; 80(2): 179-185.

59. Chen RH, Sarnecki C, Blenis J. Nuclear localization and regulation of erk- and rsk-encoded protein kinases. Mol Cell Biol 1992; 12: 915-927.

60. Greene LA, Burstein DE, Black MM. The role of transcriptiondependent priming in nerve growth factor promoted neurite outgrowth. Dev Biol 1982; 91: 305-316.

61. Chao MV. Growth factor signaling: where is the specificity? Cell 1992a; 68: 995-997.

62. Greenberg ME, Greene LA, Ziff EB. Nerve growth factor and epidermal growth factor induce rapid transient changes in protooncogene transcription in PC12 cells. J Biol Chem 1985; 260: 14101-14110.

63. Sheng M, Greenberg ME. The regulation and function of $c$-fos and other immediate early genes in the nervous system. Neuron 1990; 4: 477-485.

64. Herschman H. Primary response genes induced by growth factor and tumor promoters. Annu Rev Biochem 1991; 60: 281-319.

65. Curran T, Franza BRJ. Fos and Jun: the AP-1 connection. Cell 1988; 55: 395-397.

66. Johnson RS, Spiegelman BM, Papaioannou VE. Pleitropic effects of a null mutation in the $c$-fos proto-oncogene. Cell 1992; 74: $577-586$.

67. Morgan JI, Curran T. Stimulus-transcription coupling in the nervous system: involvement of the inducible proto-oncogenes fos and jun. Ann Rev Neurosci 1991; 14: 421-451

68. Greenberg ME, Hermanowski AL, Ziff EB. Effect of protein synthesis inhibitors on growth factor activation of $c-f o s, c-m y c$, and actin gene transcription. Mol Cell Biol 1986; 6: 1050-1057.

69. Treisman R. Transient accumulation of c-fos RNA following serum stimulation requires a conserved 5 ' element and $c$-fos $3^{\prime}$ sequences. Cell 1985; 42: 567-574.

70. Hayes TE, Kitchen AM, Cochran BH. Inducible binding of a factor to the $c$-fos regulatory region. Proc Natl Acad Sci USA 1987; 84: 1272-1276.

71. Sheng M, Dougan ST, McFadden G, Greenberg ME. Calcium and growth factor pathways of $c$-fos transcriptional activation require distinct upstream regulatory sequences. Mol Cell Biol 1988; 8: 2787-2796.

72. Sassone-Corsi P, Visvader J, Ferland L, Mellon P, Verma IM. Induction of proto-oncogene fos transcription through the adenylate cyclase pathway: characterization of a cAMP-response element. Genes Dev 1988; 2: 1529-1538.

73. Fisch TM, Prywes R, Roeder RG. c-fos sequences necessary for basal expression and induction by epidermal growth factor, 12O-tetradecanoyl phorbol-13-acetate, and the calcium ionophore. Mol Cell Biol 1987; 7: 3490-3496.

74. Berkowitz LA, Riabowal KT, Gilman MZ. Multiple sequence elements of a single functional class are required for cyclic AMP responsiveness of the mouse $c$-fos promoter. Mol Cell Biol 1989; 9: 4272-4281.

75. Treisman R. The serum response element. Trends Bioch Sci 1992; 17: 423-426.

76. Treisman $\mathrm{R}$. Identification of a protein binding site that mediates transcriptional response of the cfos gene to serum factors. Cell 1986; 46: 567-574.

77. Gilman MZ, Wilson RN, Weinberg RA. Multiple protein binding sites in the 5'-flanking region regulate cfos expression. Mol Cell Biol 1986; 6: 4305-4315.

78. Greenberg ME, Siegfried Z, Ziff EB. Mutation of the $c$-fos gene dyad symmetry element inhibits serum inducibility of transcription in vivo and the nuclear regulatory factor binding in vitro. Mol Cell Biol 1987; 7: 1217-1225.

79. Rivera VM, Sheng M, Greenberg ME. The inner core of the serum response element mediates both the rapid induction and subsequent repression of $c$-fos transcription following serum stimulation. Genes Dev 1990; 4: 255-268.

80. Bonni A, Ginty DD, Dudek H, Greenberg ME. Serine 133-phosphorylated CREB induces transcription via a cooperative mechanism that may confer specificity to neurotrophin signals. Mol Cell Neurosci 1995; 6(2): 168-183.

81. Rivera VM, Miranti CK, Misra RP, et al. A growth factor-induced kinase phosphorylates the serum response factor at a site that regulates its DNA-binding activity. Mol Cell Biol 1993; 13: 6260-6273.

82. Miranti CK, Ginty DD, Huang G, Chatila T, Greenberg ME. Calcium activates serum response factor-dependent transcription by a Ras- and Elk-1-independent mechanism that involves a Ca2+/calmodulin-dependent kinase. Mol Cell Biol 1995; 15(7): 3672-3684.

83. Dalton S, Treisman R. Characterization of SAP-1, a protein recruited by serum response factor to the $c$-fos serum response element. Cell 1992; 68: 597-612.

84. Hipskind RA, Rao VN, Mueller CG, Reddy ESP, Nordheim A. Ets-related protein Elk-1 is homologous to the c-fos regulatory factor p62 TCF. Nature 1991; 354: 531-534.

85. Gille R, Sharrocks AD, Shaw PE. Phosphorylation of transcription factor p62 $2^{\mathrm{TCF}}$ by MAP kinase stimulates ternary complex formation at the $c$-fos promoter. Nature 1992; 358: 414-417.

86. Marais R, Wynne J, Treisman R. The SRF accessory protein Elk-1 contains a growth factor-regulated transcriptional activation domain. Cell 1993; 73: 381-393.

87. Zinck R, Hipskind RA, Pingoud V, Nordheim A. c-fos transcriptional activation and repression correlate temporally with the phosphorylation status of TCF. EMBO J 1993; 12: 2377-2387.

88. Ryan WA, Franza Jr. BR, Gilman MZ. Two distinct cellular phosphoproteins bind to the $c$-fos serum element. EMBO J 1989; 8: $1785-1792$.

89. Walsh K. Cross-binding of factors to functionally different promoter elements in $c$-fos and skeletal actin genes. Mol Cell Biol 1989; 9: 2191-2201. 
90. Natesan S, Gilman MZ. DNA bending and orientation-dependent function of YYI in the c-fos promoter. Genes Dev 1993; 7: 2497-2509.

91. Gualberto AD, LePage G, Pons SL, et al. Functional antagonism between $\mathrm{YYI}$ and the serum response factor. Mol Cell Biol 1992; 12: 4209-4214.

92. Natesan S, Gilman M. YYl facilitates the association of serum response factor with the $c$-fos serum response element. Mol Cell Biol 1995; 15(11): 5975-5982.

93. Gruenberg DA, Natesan S, Alexandre C, Gilman MZ. Human and Drosophila homeodomain proteins that enhance the DNA-binding activity of serum response factor. Science 1992; 257: 1089. 1094.

94. Ginty DD, Bonni A, Greenberg ME. NGF activates a Ras-dependent protein kinase that stimulates $c$-fos transcription via phosphorylation of CREB. Cell 1994; 77: 713-725.

95. Fisch TM, Prywes R, Simon MC, Roeder RG. Multiple sequence elements in the $c$-fos promoter mediate induction by cAMP. Genes Dev 1989; 3: 198-211.

96. Brindle PK, Montminy MR. The CREB family of transcription factors. Cur Opin Gen Dev 1992; 2: 199-204.

97. Meyer TE, Habener JF. Cyclic adenosine 3',5'-monophosphate response element binding protein (CREB) and related transcription-activating deoxyribonucleic acid-binding proteins. Endocrine Rev 1993; 14: 269-290.

98. Sheng ME, Thompson MA, Greenberg ME. CREB: a Ca ${ }^{+2}$-regulated transcription factor phosphorylated by CaM kinases. Science 1991; 252: 1427-1430.

99. Gonzalez GA, Montminy MR. Cyclic AMP stimulates somatostatin gene transcription by phosphorylation of CREB at Serine 133. Cell 1989; 59: 675-680.

100. Xing J, Ginty DD, Greenberg ME. Coupling of the Ras-MAPK pathway to gene activation by RSK2, a growth factor-regulated CREB kinase. Science 1996; 273: 959-963.

101. Chrivia JC, Kwok RPS, Lamb N, et al. Phosphorylated CREB binds specifically to the nuclear protein CBP. Nature 1993; 365 : 855-859.

102. Kwok RPS, Lundblad JR, Chrivia JC, et al. Nuclear protein CBP is a coactivator for the transcription factor CREB. Nature 1994; 370: $223-226$

103. Traverse S, Seedorf K, Paterson H, et al. EGF triggers neuronal differentiation of $\mathrm{PC} 12$ cells that overexpress the EGF receptor. Curr Biol 1994; 4: 694-701.

104. Hu Q, Klippel A, Muslin AJ, Fantl WJ, Williams LT. Ras-dependent induction of cellular responses by constitutively active phosphatidylinositol-3 kinase. Science 1995; 268: 100-102.

105. Yao R, Cooper GM. Requirement for phosphatidylinositol-3 kinase in the prevention of apoptosis by nerve growth factor. Science 1995; 267: 2003-2006.

106. Divecha N, Irvine RF. Phospholipid signaling. Cell 1995; 80: 269278.

107. Franke TF, Kaplan DR, Cantley LC. PI3K: downstream AKTion blocks apoptosis. Cell 1997; 88: 435-437.

108. Burgering B, Coffer P. Protein kinase B (Akt) in phosphatidylinositol-3-OH kinase signal transduction. Nature 1995; 376: 599-602.

109. Franke TF, Yang SI, Chan TO, et al. The protein kinase encoded by the Akt proto-oncogene is a target of the PDGF-activated phosphatidylinositol 3-kinase. Cell 1995; 81: 727-736.

110. Dudek H, Datta SR, Franke TF, et al. Regulation of neuronal survival by the serine-threonine protein kinase Akt. Science 1997; 275: 661-665.
111. Chung J, Grammer T, Lemmon K, Kazlauskas A, Blenis J. PDGF and insulin-dependent $p p 70^{\dot{s} 6 \mathrm{~K}}$ activation mediated by phosphatidylinositol-3-OH kinase. Nature 1994; 370: 71-75.

112. de Groot RP, Ballou LM, Sassone-Corsi P. Positive regulation of the cAMP-responsive activator CREM by the p70 S6 kinase: an alternative route to mitogen-induced gene expression. Cell 1994; 79: $81-91$.

113. Rabin S, Cleghorn V, Kaplan DR. SNT, a differentiation-specific target of neurotrophic factor-induced tyrosine kinase activity in neurons and PC12 cells. Mol Cell Biol 1993; 13: 2203-2213.

114. Peng X, Greene L, Kaplan DR, Stephens R. Deletion of a conserved juxtamembrane sequence in Trk abolishes NGF-promoted neuritogenesis. Neuron 1995; 15: 395-406.

115. Hill CS, Treisman R. Transcriptional regulation by extracellular signals: mechanisms and specificity. Cell 1995; 80: 199-21l.

116. Gupta S, Campbell D, Derijard B, Davis RJ. Transcription factor ATF2 regulation by the JNK signal transduction pathway. Science 1995; 267: 389-393.

117. Whitmarsh AJ, Shore P, Sharrocks AD, Davis RJ. Integration of MAP kinase signal transduction pathways at the serum response element. Science 1995; 269: 403-407.

118. Vojtek A, Cooper JA. Rho family members: activators of MAP kinase cascades. Cell 1995; 82: 527-529.

119. Xia Z, Dickens M, Raingeaud J, Davis RJ, Greenberg ME. Opposing effects of ERK and JNK-p38 MAP kinases on apoptosis. Science 1995; 270: 1326-1334.

120. Verheij M, Bose R, Lin XH, et al. Requirement for ceramide-initiated SAPK/JNK signalling in stress-induced apoptosis. Nature 1996; 380: 75-79.

121. Joseph C, Byun H, Bittman R, Kolesnick R. Substrate recognition by ceramide-activated protein kinase. J Biol Chem 1994; 268: 20002-20006.

122. Yao B, Zhang Y, Delikat S, et al. Phosphorylation of Raf by ceramide-activated protein kinase. Nature 1995; 378: 307-310.

123. Dobrowsky RT, Werner MH, Castellino AM, Chao MV, Hannun YA. Activation of the sphingomyelinase cycle through the lowaffinity neurotrophin receptor. Science 1994; 265: 1596-1599.

124. Barker PA, Shooter EP. Disruption of NGF binding to the low affinity neurotrophin receptor $\mathrm{p} 75$-LNTR reduces NGF binding to TrKA on PC12 cells. Neuron 1994; 13: 203-215.

125. Davies AM, Lee K-F, Jaenisch R. p75-deficient trigeminal sensory neurons have an altered response to NGF but not to other neurotrophins. Neuron 1993; 11 : 565-574.

126. Rabizadeh S, Oh J, Zhong LT, et al. Induction of apoptosis by the low-affinity NGF receptor. Science $1993 ; 261: 345-348$.

127. Van der Zee CEEM, Ross GM, Riopelle RJ, Hagg T. Survival of cholinergic forebrain neurons in developing p75 ${ }^{\text {NGFR }}$-deficient mice. Science 1996; 274: 1729-1732.

128. Feinstein E, Kimchi A, Wallach D, Boldin M, Varfolomeev E. The death domain: a module shared by proteins with diverse cellular functions. Trends Biochem Sci 1995; 20: 342-344.

129. Anton ES, Weskamp G, Reichardt LF, Matthew WD. Proc Natl Acad Sci USA 1994; 91: 2795-2799.

130. Petrij F, Giles RH, Dauwerse HG, et al. Rubinstein-Taybi syndrome caused by mutations in the transcriptional co-activator CBP. Nature 1995; 376(6538): 348-351

131. Trivier E, De Cesare D, Jacquot $S$, et al. Mutations in the kinse Rsk-2 associated with Coffin-Lowry syndrome. Nature 1996; 384: $567-570$. 